\title{
CO-OCCURRENCE PATTERN OF GROUND BEETLE (COLEOPTERA, CARABIDAE) INDICATES THE QUALITY OF RESTORATION PRACTICES IN POSTINDUSTRIAL AREAS
}

\author{
KĘDZIOR, R. \\ University of Agriculture in Krakow, Department of Ecology, Climatology and Air Protection \\ Al. Mickiewicza 24/28, 30-059 Krakow, Poland \\ (e-mail: r.kedzior@ur.krakow.pl; phone: +48 12 662-41-33) \\ (Received $13^{\text {th }}$ Aug 2018; accepted $11^{\text {th }}$ Oct 2018)
}

\begin{abstract}
Co-occurrence pattern is a good indicator of environmental changes, being a consequence of human industrial activity. A good model of co-occurrence mechanisms is the degree of species ordering in the assemblage, which indicates the existence of interspecific interactions such as competition for available resources. The aim of the study was to assess the co-occurrence of ground beetles as a parameter evaluating the effectiveness of ecosystem restoration processes in postindustrial areas. In addition, the distribution of the beetles' body size pattern in the environmental types was assessed. Responses of carabid co-occurrence patterns to restoration practice in three types of environments: recultivated, spontaneously regenerated and reference forest were investigated. C-score index as a coefficient of co-occurrence, and Lorenz curves, skewness and kurtosis coefficients of body size distribution reflected the succession stage. The carabid assemblages from the references and spontaneously restoring sites showed a significant segregation pattern. Community disassembly occurred only among assemblages of recultivated sites. The body size distribution of Carabidae in recultivated areas indicated the lowest share of large, forest species characteristics of stable ecological systems. The results emphasize the usefulness of the co-occurrence index for the evaluation of the effectiveness of restoration treatments in post-industrial areas.
\end{abstract}

Keywords: C-score, null models, carabids, body size, recultivation, spontaneous succession

\section{Introduction}

Environmental monitoring of postindustrial areas is one of the most important tools for assessing the state of disturbed environment. Very often is also used to assess the effect of restoration practices, which are most often the effect of recultivation techniques or, less often, the effect of spontaneous succession (Hadcova and Prach, 2003; Frouz et al., 2008). The use of bioindicators to study the rate and efficiency of regeneration of disturbed environments help to restoration advances and allow a reliable diagnosis about the course of environmental changes (Hedde et al., 2012; Pedley and Dolman, 2014).

Among the large group of environmental bioindicators, restoration ecologists often use beetles from the family Carabidae (Coleoptera), which play an important role in nutrient cycling and in the establishment of appropriate food webs (Koivula, 2011; Ribas et al., 2012; Skalski et al., 2015; Skłodowski, 2017a). Moreover, they often indicate the overall quality of the ecosystem in which they occur (Kędzior et al., 2017). Ground beetles have many features of good indicator organisms, they are abundant in each terrestrial ecosystems and what's more they are functionally various group with narrow ecological ranges and high sensitivity to environmental changes (Rainio and Niemelä, 2003). They also can respond more quickly and rapidly to environmental change than other organisms (Pais and Varanda, 2010). In addition, their ecology and systematics is well known and field survey is quite simple as well as successional patterns has been shown detaily in naturally regenerated ecosystems (Hodecek et al., 2015; Skłodowski, 2017b). 
Based on the assemblage parameters (abundance, species richness, species diversity indices) of ground beetles, it is possible to assess the state of the environment and indicate the effects of restoration practices (Kędzior et al., 2014, 2017). In addition, the functional parameters of these insects are also increasingly being analyzed (body size, dispersion power, food preferences, developmental type). Occurrence of species with specific life traits parameters accurately characterizes the condition of the ecosystem (Kosewska, et al., 2014; Pedley and Dolman, 2014; Skalski et al., 2016). For example the analysis of dispersal power and the body size allows to determine the possibilities of adaptation or recolonization, while food preferences indicate the availability of food resources and food specialization in the environment (Lövei and Sunderland, 1996).

We should also regard about inter-specific relations in ground beetle assemblages that vary in natural and disturbed ecosystems (Skalski et al., 2010, 2011). Species traits and habitat parameters (capacity rules) as well as species interactions (allocation rules) seems to be the most important factors determining assemblages (Brown, 1987). Null models have been often used to investigate patterns in species distributions and co-occurrences (Gotelli, 2000; Gotelli and Ellison, 2002; Sanders et al., 2007). The species structure of Carabidae in undisturbed systems usually depends on many factors. These organisms as epigeic fauna depend strongly on soil parameters (physico-chemical parameters) that determine the habitat, but also on the nutrient resources available in the environment and interspecies relationships, such as competition (Thiele, 1977).

In the undisturbed environment, the occurring species have ordered pattern of distribution in which trophic relations and the degree of competition for available resources are defined (Stone and Roberts, 1990). However, when a disturbance occurs in the environment, the reaction of organisms is visible as species exchange. Species with high ecological sensitivity are eliminated from the ecosystem, while the proportion of species with broad ecological range increases. The ecological systems created in this way are disturbed, and the occurrence of certain species indicates the randomness, where interspecific relations are weak (Sanders et al., 2007). This phenomenon leads to unification and deterioration of the functionality of the entire ecosystem. Therefore, the analysis of the species co-occurrence of ground beetles can be an excellent tool indicating the level of disturbances and the possibility of restoration of interspecies interactions, which are important for the functioning of the entire ecosystem.

The aim of the study was to assess the co-occurrence pattern and body size distribution of Carabidae species as a parameters evaluating the effectiveness of ecosystem restoration processes in post-industrial areas. The following research hypotheses were tested: (I) in the recultivated habitats random species distribution of ground beetles assemblages occurs, and high proportion of small-sized species with low competitive properties should be expetced; (II) in areas regenerating spontaneously, the co-occurrence pattern of assemblages take the form of ordered systems remaining relations as in undisturbed ecosystems and proportion of forest carabid specialists increases.

\section{Materials and Methods}

\section{Study sites}

The study was conducted in post-industrial areas of Southern Poland in the vicinity of Krakow (Fig. 1), where two recultivated (Rec) $\left(50^{\circ} 09^{\prime} \mathrm{N}, 19^{\circ} 25^{\prime} \mathrm{E}\right.$ and $49^{\circ} 58^{\prime} \mathrm{N}$, $\left.19^{\circ} 46^{\prime} \mathrm{E}\right)$ and two spontaneously regenerated dumps (Suc) $\left(50^{\circ} 13^{\prime} \mathrm{N}, 19^{\circ} 27^{\prime} \mathrm{E}\right.$ and $\left.50^{\circ} 10^{\prime} \mathrm{N}, 19^{\circ} 27^{\prime} \mathrm{E}\right)$ were selected. Two forest areas regarded as reference areas (Ref) 
were also chosen $\left(49^{\circ} 57^{\prime} \mathrm{N}, 1^{\circ} 45^{\prime} \mathrm{E}\right.$ and $\left.50^{\circ} 11^{\prime} \mathrm{N}, 19^{\circ} 30^{\prime} \mathrm{E}\right)$ (Fig. 1). Recultivated dumps (Rec) at the age of about 20 years were characterized by a large proportion of trees and shrubs with low environmental requirements, e.g. silver birch (Betula pendula), black locust (Robinia pseudoacacia), european aspen (Populus tremula) and mountain ash (Sorbus aucuparia), which were planted on the bunds of dumps in a regular pattern. The species composition of trees and shrubs in spontaneously regenerating dumps (Suc) was similar to the species composition of plant assemblages from neighboring areas (Betula pendula, Robinia pseudoacacia, Populus tremula, common Sorbus aucuparia and Pinus silvestris). References (Ref) were, however, habitats of mixed fresh forests. The content of heavy metals in soil did not differ significantly between the particular research areas (Kędzior et al., 2017). The distance between individual areas ranged from $3-50 \mathrm{~km}$. The areas adjacent to the dump sites selected for research were of agro-industrial character.

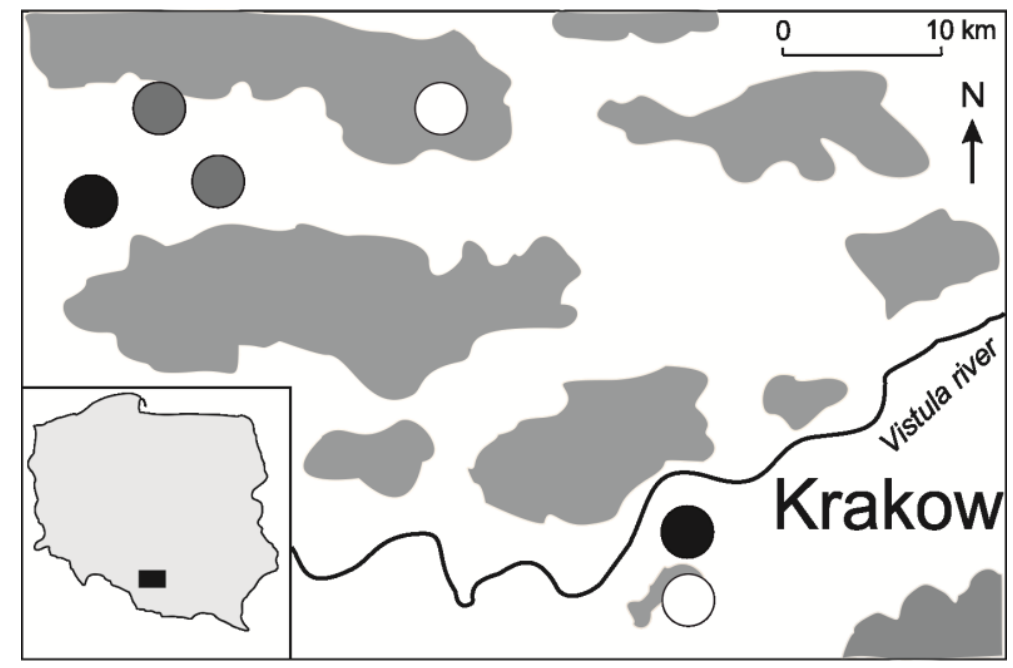

Figure 1. Location of the study areas. The circles indicate as follows: black - recultivated dumps, dark grey - dumps with spontaneous succession and white-reference forests. The patches indicate forest areas

\section{Carabid sampling}

The ground beetles were collected using pitfall traps arranged in 45 transects. A single transect consisted of 5 Barber traps (plastic cups with a diameter of $7 \mathrm{~cm}$ and a height of $10 \mathrm{~cm}$, buried evenly with the surface of the earth, filled in $1 / 3$ with ethylene glycol) arranged linearly at intervals of 10 meters. In each research area, depending on its area size and heterogenity, in order to avoid edge effect and spatial autocorrelation (SAM software v 4.0, Moran's $I=0.072, p=0.48$ ), the distance between transects varied from $200 \mathrm{~m}$ to $50 \mathrm{~km}$ (Kędzior et al., 2017). In total 10-20 replicates of transects per restoring habitat type were chosen. There were ten replicates of transects in three dumps which were heterogenous and large enough (minimum distance between transects should be $200 \mathrm{~m}$ ). In one afforested landfill and two reference forest which were visibly homogenous we decided to apply five replicates of transects. The abundances were calculated as mean abundance per pitfall trap row (transect). Beetle samples were collected four times in the growing season from May to June and from September to mid-October in 2013 and 2015. For the summer period (because of low activity of 
carabids) the pitfall traps were closed and reopened in the begining of September. Collected individuals were identified to the species level using Hurka key (1996). The average body size was determined for each species from data available in the Carabidae keys (Hurka, 1996).

\section{Data analysis}

For each habitat type (Ref - reference, Rec - recultivation and Suc - spontaneous succession) the co-ocurrence pattern was analyzed by Stone and Roberts (1990) C-score formula:

$$
\mathrm{Cij}=(\mathrm{ri}-\mathrm{S})(\mathrm{rj}-\mathrm{S})
$$

where ri - row total for species $\mathrm{i}$; rj - row total for species $\mathrm{j} ; \mathrm{S}$ - number of sites that contain both species ( $\mathrm{i}$ and $\mathrm{j}$ ) (Heino, 2009). Among the available indices of cooccurrence estimation, $\mathrm{C}$ - score index is the most recommended as indicating pattern of distribution (randomness or nestedness (Gotelli, 2000). The data used in analyses were prepared in a presence-absence matrix with species (rows) by sites $(n=45)$. C-score provided a measure of co-occurence within the matrices. The $\mathrm{C}$-score was calculated for each habitat type (Ref, Suc and Rec), measuring the average pairwise species cooccurrence and if assemblages are structured by competition the $\mathrm{C}$-score should be larger than expected by chance (EcoSim software, Gotelli and Entsminger, 2001). The histogram of $10000 \mathrm{C}$-scores from fixed-fixed null model was used to test variety of ecological processes. In the fixed-fixed null model the row and column sums are fixed in the null community. For example each random postindustrial site contained the same number of species as the original site and each species occurred in the same frequency as in the original assemblages (Gotelli and Ellison, 2002). In that way the number of species and species occurrences are the same as the observed community.

In order to determine the dependence of competitors among ground beetle species, the distribution of body size in habitat types was examined. To determine if there are differences in body size distribution depending on restoration practice, modified Lorenz curves (Ulrich et al., 2008), skewness and kurtosis ratios for each habitat type were developed (Magura et al., 2006). The significance of skewness and kurtosis among habitat variables was calculated by ANOVA (StatSoft, 2012). To analyze the similarities between the ground beetle species a hierarchical cluster analysis was carried out using PAST v. 3.19 (Hammer et al., 2001), with Euclidian distance as distance measure and agglomeration according to Ward. The abundance values of the species at the respective habitat type (Ref, Suc and Rec) were used. The strength of the nodes was tested by bootstrapping analysis (1999 re-samplings). Bootstrap proportions (percentage of replicates where the node is still supported) of $\geq 70 \%$ correspond to a probability of $\geq 95 \%$ that the respective clade is correct (Hillis and Bull, 1993).

\section{Results}

During collecting time 2036 individuals belonging to 36 carabid species were caught. The C-score values indicated significant differences in the co-occurrence pattern in carabid assemblages among three environmental types (Ref, Suc and Rec) (Table 1). In reference areas (Ref) the co-occurrence pattern showed a non-random pattern, the mean simulated $\mathrm{C}$-score value was significantly lower than the value generated for the 
empirical data (Fig. 2, Table 1). A similar pattern of coexistence was noted in the postindustrial areas regenerating spontaneously (Suc). As in the reference areas, mean simulated values of C-score were significantly lower compared to the value of observed C-score (Fig. 2, Table 1).

Such a result indicates the existence of strong interspecies interactions, such as competition, characterizing undisturbed systems. A different pattern of species coexistence was noted only for regenerating $(\mathrm{Rec})$. The simulated C-score did not differ significantly from the generated mean random occurrence (Fig. 2, Table 1).

Table 1. Summarized results of co-occurrence analysis for three habitat types: reference forests, dumps with spontaneous succession and recultivated dumps

\begin{tabular}{c|c|c|c|c|c}
\hline Localities & Abbr. & $\begin{array}{c}\text { Observed } \\
\text { C-score }\end{array}$ & $\begin{array}{c}\text { Simulated } \\
\text { Means }\end{array}$ & Variance & p-value \\
\hline Reference forest & Ref & 2.39 & 2.30 & 0.001 & 0.012 \\
Spontaneous succession & Suc & 14.45 & 14.07 & 0.009 & 0.002 \\
Recultivated dump & Rec & 3.98 & 3.95 & 0.004 & 0.324 \\
\hline
\end{tabular}
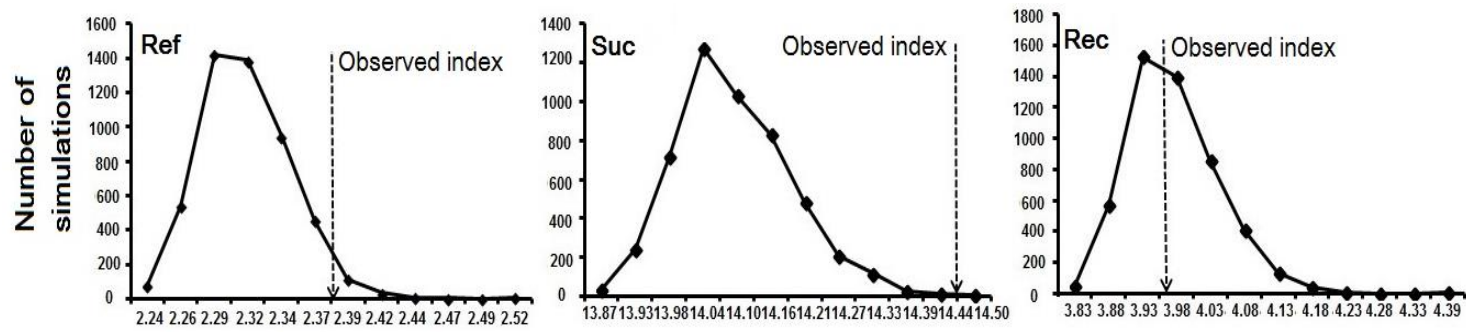

C-score values

Figure 2. Histogram of the observed and expected $C$-score values in studied areas (Refreference forests, Suc-dumps with spontaneous succession, Rec-recultivated dumps)

Body size distributions of ground beetle assemblages analysed according to the modified Lorenz curves showed strong variation depending on the type of environment (Fig. 3). Higher proportion of large and medium-sized body species were found in reference assemblages (Fig. 3a), while in spontaneously regenerating (Fig. 3b) and recultivated (Fig. 3c) assemblages, a higher proportion of small and medium sized species was observed.

Comparing all of the habitat types, the greater similarity in the distributions of the modified Lorenz curves to the reference areas was noted for assemblages reclaiming as a result of natural processes. A clear habitat type variation in body size distributions was also noted in the skewness and kurtosis indicators (Table 2). Skewness and kurtosis were significantly the highest in the recultivated areas and the lowest in the reference forests (Fig. 4). 

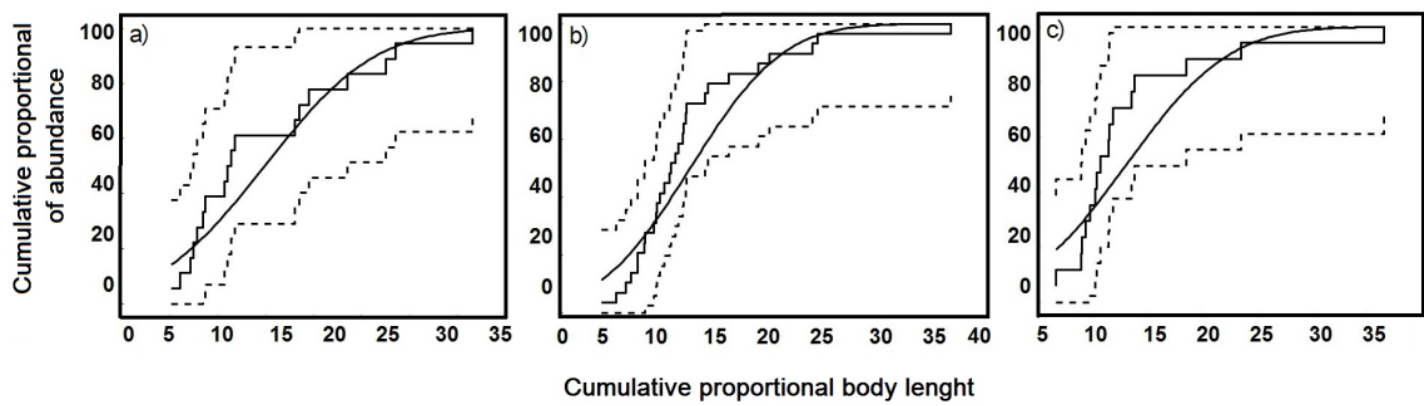

Figure 3. Modified Lorenz curves of the body size distribution of ground beetles in reference forests (a), dumps with spontaneous succession (b), and recultivated dumps (c) (dotted line- the intervals of probability, smooth line - the assumption of the data distribution and broken linethe strict relation between variables)

Table 2. The result of one-way Anova for the values describing the shape of the body size distribution pattern in ground beetle assemblages. Significance level: $* p<0.05, * * p<0.01$, $* * * p<0.001$

\begin{tabular}{cc|c|c|c|c|c}
\hline \multicolumn{2}{c|}{ Body size variables } & SS & df & MS & F & p \\
\hline \multirow{4}{*}{ Skewness } & Residual & 566.92 & 1 & 566.92 & 800.06 & $* * *$ \\
& Environmental type & 18.87 & 2 & 9.43 & 12.31 & $* * *$ \\
& Error & 26.21 & 37 & 0.71 & & \\
\hline \multirow{2}{*}{ Kurtosis } & Residual & 11248.15 & 1 & 11248.15 & 200.24 & $* * *$ \\
& Environmental type & 1465.07 & 2 & 732.53 & 13.04 & $* * *$ \\
& Error & 2078.37 & 37 & 56.17 & & \\
\hline
\end{tabular}
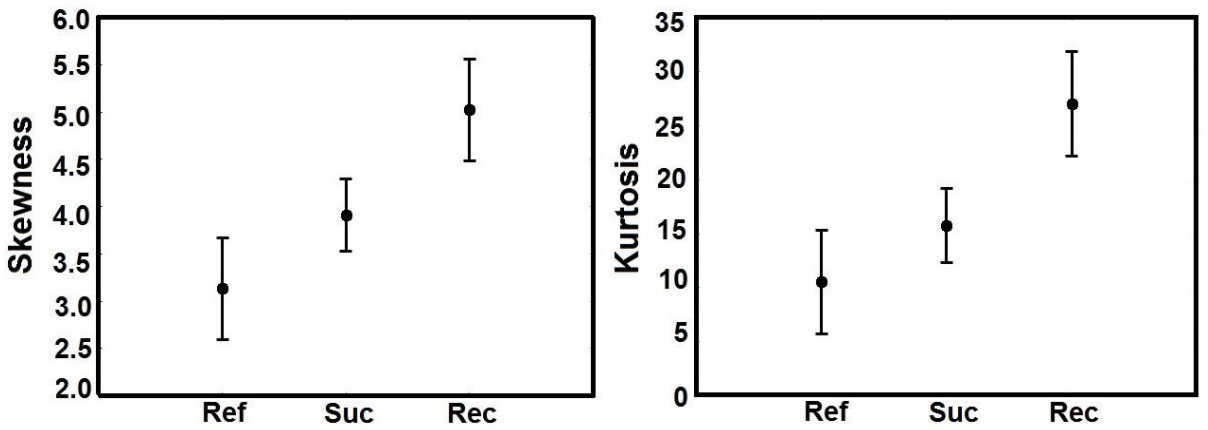

Figure 4. Mean ( \pm S.E.) skeweness and kurtosis coefficients for the ground beetle assemblages in studied sites (Ref-reference forest, Rec-recultivated dump, Suc-dump in succession)

The species from recultivated dumps (Fig. 5, Rec) clearly divided only Harpalus rufipes (group A) from the rest of species (B) which are highly aggregated. Stronger segregation between species is visible on dump in succession (Fig. 5, Suc). Three groups of species were distinguished. The first cluster (A) is occupied by one species Calathus erratus, typical for disturbed areas. The second cluster (B) consist of a large 
number of ground beetle species with similar pattern of random distribution, while the third cluster (C) includes forest species (Pterostichus niger, Pt. oblongopuncatus, Leistus rufomarginatus). The cluster of ground beetles inhabiting reference forests (Ref) also show the three groups of species, however it reveals much more variable pattern (Fig. 5, Ref).

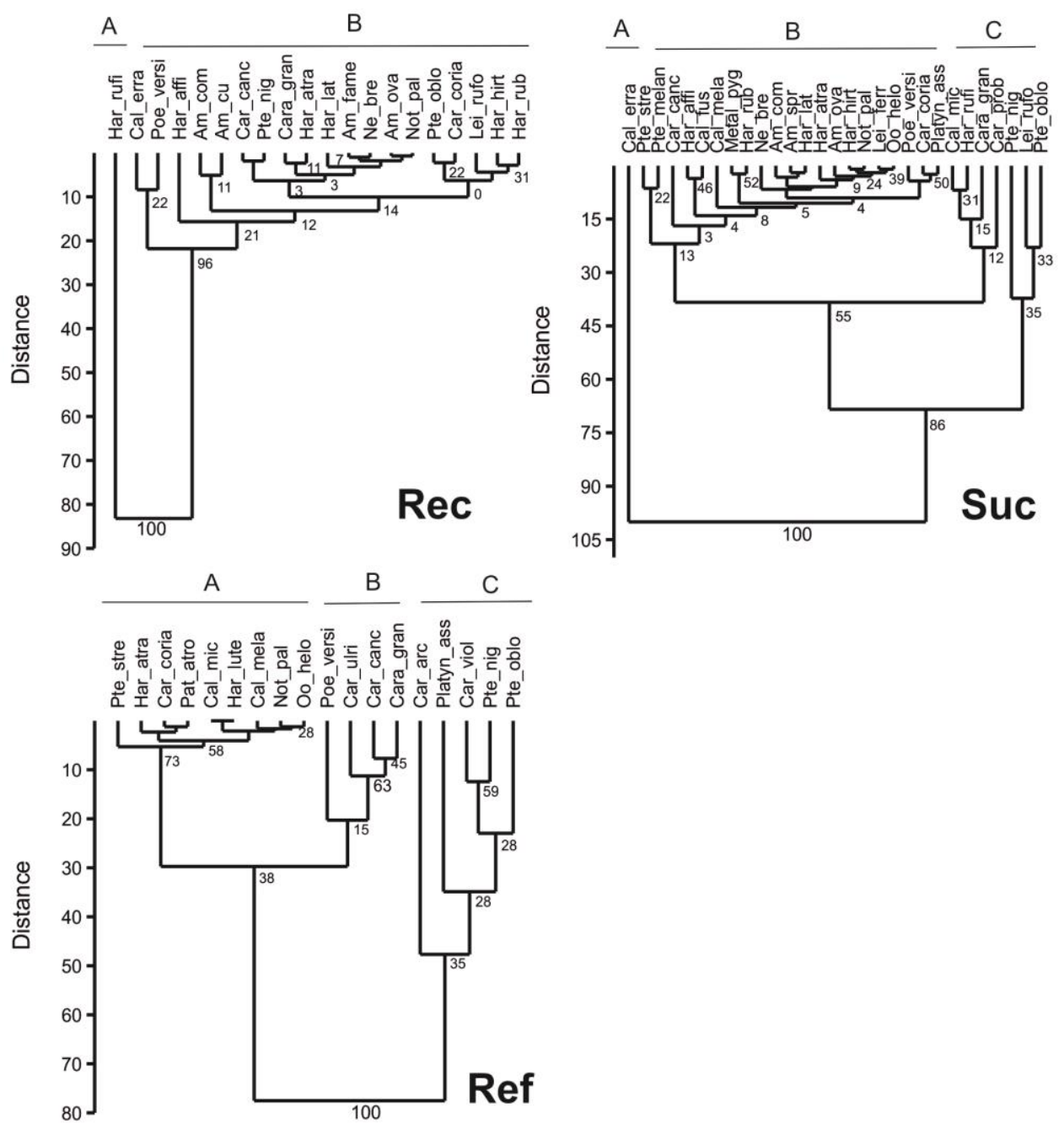

Figure 5. Cluster analysis of the results based on Euclidian distance as distance measure and agglomeration according to Ward for recultiaveted, (Rec), spontaneously successed (Suc) and reference areas (Ref). Numbers indicate the percentage of replicates where each node is still supported

The first cluster includes species with broad ecological ranges, which are mostly open area invaders. On the other hand, the second and third cluster (B and C) mainly includes species that prefer forest habitats, and a large distance indicates the occurrence of interspecies interactions between these species, e.g. competition. The average Euclidean distance between species in particular habitat type, reflecting the niche overlap indicate the gradient of species coexistence, from the highest on reference sites 
to the lowest in recultivated habitats (Fig. 6). In all the cases the differences between means were significant.

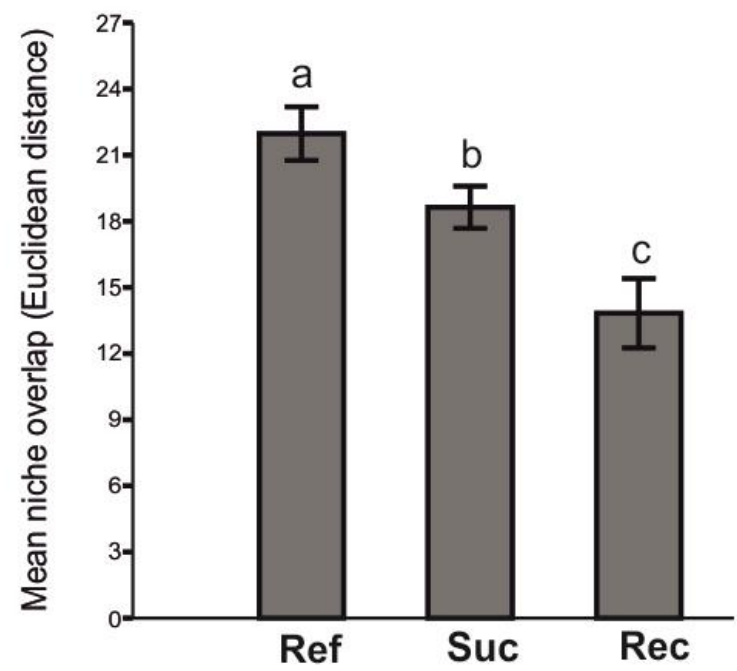

Figure 6. Mean niche overlap of ground beetle species based on Euclidian distance as distance measure and agglomeration according to Ward for reference areas (Ref), with spontaneous succession (Suc) and recultivation practice (Rec). Significance (Mann-Whitney U test) differences are marked by appropriate letter

\section{Discussion}

There are many adverse changes in industrial areas. They can refer to many different aspects, for example chemical pollution of soils, water or air. The impact of industrial human activity interferes also with the land forms by deforming the earth's surface or forming new elements such as excavations and dumps. Degradation of existing habitats and the creation of new systems with severely disturbed environmental parameters is often the cause of the elimination of many species of native plants and animals as well as the general decline in biodiversity (Vandewalle et al., 2010). The rate of recolonization in such environments is often very difficult to define and depends on many factors (habitat parameters, availability of resources, species richness of adjacent areas) and the types of undertaken restoration practices (Skalski and Pośpiech, 2006; Tropek et al., 2012; Skalski et al., 2016). In many cases, postindustrial areas are recultivated by planting trees in regular patterns. There are also areas where natural regeneration occurs spontaneously (Hodecek et al., 2015; Laarman et al., 2015).

In order to assess or monitor the rate and effectiveness of regeneration processes in such areas, indicators should be applied that would accurately reflect this process. In presented paper, ground beetles (Coleoptera, Carabidae) were used as bioindicators for assessing the rate and efficiency of ecosystem restoration in postindustrial areas. The co-occurrence pattern of assemblages was analyzed in two types of restoring environment (recultivation and spontaneous processes) and in reference forest. The results showed that co-occurrence pattern of species in assemblages in relation to ecosystem regeneration is very good indicator of restoration practices (Fig. 2). If the distribution of species in space and time is characterized by randomness, it indicates an imbalance in the assemblages where the interspecific interactions are disturbed. It may 
characterize strongly disturbed ecosystems (Fig. 2, Rec). If, on the other hand, the cooccurrence of species in assemblage is ordered, and there are many interspecies interactions such as competition or exclusions, it is a good indicator of environment stability (Fig. 2, Suc).

The values of the $\mathrm{C}$-score index indicate that regeneration of post-industrial areas through spontaneous natural processes is more successive in comparison to the areas where tree plantation are replanted (Table 1). In recultivated areas, even after 20 years, the co-occurrence pattern of ground beetles is still characterized by random distribution, which clearly indicates the presence of abnormal ecological processes (Fig. 2). However, in areas that restoring spontaneously, the co-occurrence of carabids has an ordered pattern (Fig.2). According to many authors, spontaneous processes are more beneficial to restore the diversity and richness of species, which may be the cause of greater habitat heterogeneity of regenerating habitats, compared to homogeneous structures in recultivated areas (Hadcova and Prach, 2003; Frouz et al., 2008; Kędzior et al., 2017). In addition, in the areas of spontaneous regeneration the complexity of various trophic level occurs (Tropek et al., 2010). During such succession, there is a change in assemblage composition towards the increase of the proportion of species requiring stable environmental conditions (Schwerk, 2014; Hodecek et al., 2015). These species with large body sizes and low dispersal power, as a group (consisting predominantly of predators) plays an important role in the functioning of ecosystems (so-called environmental specialists) (Skłodowski, 2009).

Examining body size distributions and the similarity of species composition in each of the three types of habitats (Ref, Suc and Rec) a variation in successional changes of carabid assemblages was noticed. In undisturbed reference forest areas, the proportion of species with the largest body sizes is visible, which are clearly distinguished in cluster analysis (Fig. 5). They are mainly species of genus Carabus and Pterostichus. They belong to the group of environmental specialists indicating forest habitat stability (Szyszko, 1983). Comparing the assemblages of reference (Ref) and recultivated (Rec) areas, the proportion of these species is negligible, and the distribution of clusters and distances between these species indicate that they probably are distributed accidentally (Fig. 5). The main explanation of random distribution of predator assemblages in longterm disturbed habitat conditions is linked with the impoverishment suitable food base for these species (Skalski et al., 2016; Kędzior et al., 2017). The result showed also that in recultivated areas species with broad ecological ranges and small size of the body were identifed (Fig. 4, Table 2). These species (e.g. mainly Pseudophonus rufipes, Calathus erratus) can quickly adapt to the unstable environment, and because of this they belong usually to pioneer fauna (Schwerk, 2014; Kędzior et al. 2014). Moreover they feed on broad variety of food, from plant dead tissues to predation, and are the competitive dominant species in recultivated areas (Schwerk, 2014). While in reference forest occurs only occasionally (Kędzior et. al., 2017).

The aim of the study was also to explore the body size distribution of the ground beetles (Coleoptera, Carabidae) assemblages in areas characterized by various restoration processes. The distributions of the modified Lorenz curves, mean skewness and kurtosis coefficients showed differences between habitat type (Figs. 3 and 4). The proportion of large sized species in spontaneously regenerated habitats was small, but in cluster analysis separated them significantly from the rest of species in assemblage (Fig. 5 ). This pattern was completely differed in recultivated areas. The mean niche overlap in recultivated ecosystem was significantly lower than in spontaneously regenerated 
stands and reference forest (Fig. 6). It reflects the process of random species recolonization in unfavourable habitats (Gotelli and Ellison, 2002; Skalski et al., 2010).

Considerations on bioindicative methods for assessing the effectiveness and rate of restoration of the postindustrial ecsosystems were carried out by many researchers in variety ranges and using a variety of indicator organisms (Frouz et al., 2008; Hedde et al., 2012; Kędzior et al., 2014). As it is shown in these studies ground beetles are a good model group to define changes in the environment (Rainio and Niemelä, 2003; Koivula, 2011; Skalski et al., 2011). Examining the co-occurrence pattern and body size distribution of beetles, it is possible to assess the effects of regeneration methods and asses the best restoration procedure in postindustrial areas.

\section{Conclusions}

The co-occurrence pattern of ground beetle assemblages clearly assess the restoration success in postindustrial areas. Carabids from recultivated areas (Rec) showed a random pattern of co-occurrence, as an effect of high extinction rate reflecting high disturbance level. Whereas assemblages from reference areas (Ref) as well as spontaneously regenerated (Suc) showed a significant segregation pattern.

Recultivated areas were dominated by small sized species having high adaptive abilities and high ecological plasticity (Harpalus rufipes, Catalthus erratus). In areas with spontaneous succession, an increase in the proportion of large sized species was observed. My results suggest that co-occurrence pattern of ground beetle assemblages can be useful for restoration practice in postindustrial areas.

Recultivation techniques of postindustrial dumps without proper soil reclamation, inhibit the natural processes of ecosystem recovery. Postindustrial landscape planning schemes should include soil properties of biotic elements to obtain well functioning ecosystem.

Acknowledgements. The surveys were financed from the Personal Scholarship Fund for academics of the University of Agriculture in Krakow and DS-3337/KEKiOP.

\section{REFERENCES}

[1] Brown, J. H. (1987): Variation in desert rodent guilds: patterns, processes, scales. - In: Gee, J. H. R., Giller, P. S. (eds.) Organization of Communities: past and present. Blackwell, Oxford, pp 185-203.

[2] Frouz, J. K., Prach, V., Pižl, L., Háněl, J., Starý, K., Tajovský, J., Materna, V., Balík, J., Kalcík, J., Řehounková, K. (2008): Interactions between soil development, vegetation and soil fauna during spontaneous succession in post mining sites. - European Journal of Soil Biology 44: 109-121.

[3] Gotelli, N. J., Ellison, A. M. (2002): Assembly rules for New England ant assemblages. Oikos 99: 591-599.

[4] Gotelli, N. J. (2000): Null model analysis of species co-occurrence patterns. - Ecology 81: 2606-2621.

[5] Gotelli, N. J., Entsminger, G. L. (2001): EcoSim: Null models software for ecology. Version 7.0. Acquired Intelligence Inc. \& Kesey-Bear. http://homepages.together.net/ gentsmin/ecosim.htm. 
[6] Hadcova, D., Prach, K. (2003): Spoil heaps from brown coal mining: technical reclamation versus spontaneous revegetation. - Restoration Ecology 11: 385-391.

[7] Hammer, Ø., Harper, D. A. T., Ryan, P. D. (2001): Past: Paleontological Statistics Software Package for Education and Data Analysis. - Palaeontologia Electronica 4: 9.

[8] Hedde, M., van Oort, F., Lamy, I. (2012): Functional traits of soil invertebrates as indicators for exposure to soil disturbance. - Environmental Pollution 164: 59-65.

[9] Heino, J. (2009): Species co-occurrence, nestedness and guild-environment relationships in stream macroinvertebrates. - Freshwater Biology 54: 1947-1959.

[10] Hillis, D. M., Bull, J. J. (1993): An empirical test of bootstrapping as a method for assessing confidence in phylogenetic analysis. - Systematic Biology 42: 182-192.

[11] Hodecek, J., Kuras, T., Sipos, J., Dolny, A. (2015): Post-industrial areas as successional habitats: Long term changes of functional diversity in beetle communities. - Basic of Applied Ecology 16: 629-640.

[12] Hurka, K. (1996): Carabidae of the Czech and Slowak Republics. - Kabourek, Zlin.

[13] Kędzior, R., Skalski, T., Szwalec, A., Mundała, P. (2014): Diversity of carabid beetle assemblages (Coleoptera: Carabidae) in a post-industrial slag deposition area. - Baltic Journal of Coleopterology 14: 219-228.

[14] Kędzior, R., Szwalec, A., Mundała, P., Skalski, T. (2017): Ground beetle assemblages in recultivated and spontaneously regenerated forest ecosystems on post-industrial areas. Sylwan 161: 512-518.

[15] Koivula, M. J. (2011): Useful model organisms, indicators, or both? Ground beetles (Coleoptera, Carabidae) reflecting environmental conditions. - ZooKeys 100: 287-317.

[16] Kosewska, A., Skalski, T., Nietupski, M. (2014): Effect of conventional and noninversion tillage systems on the abundance and some life history traits of carabid beetles (Coleoptera: Carabidae) in winter triticale fields. - European Journal of Entomology 111: 669-676.

[17] Laarmann, D., Korjus, H., Sims, A., Kangur, A., Kiviste, A., Stanturf, J. A. (2015): Evaluation of afforestation development and natural colonization on a reclaimed mine site. - Restoration Ecology 23: 301-309.

[18] Lövei, G. L., Sunderland, K. T. (1996): Ecology and Behavior of Ground Beetles (Coleoptera: Carabidae). - Annual Review of Entomology 41: 231-256.

[19] Magura, T., Tóthmérész, B., Lövei, G. (2006): Body size inequality of carabids along an urbanisation gradient. - Basic Applied Ecology 7: 472-482.

[20] Pais, M. P., Varanda, E. M. (2010): Arthropod recolonization in the restoration of semideciduous forest in southeastern Brazil. - Neotropical Entomology 39: 198-206.

[21] Pedley, S. M., Dolman, P. M. (2014): Multi-taxa trait and functional responses to physical disturbance. - Journal of Animal Ecology 83: 1542-1552.

[22] Rainio, J., Niemelä, J. (2003): Ground beetles (Coleoptera: Carabidae) as bioindicators. Biodiversity and Conservation 12: 487-506.

[23] Ribas, C. R., Schmidt, F. A., Solar, R. R. C., Campos, R. B. F., Valentim, C. L., Achoereder, J. H. (2012): Ants as indicators of the success of rehabilitation efforts in Deposits of Gold Mining Tailings. - Restoration Ecology 20: 712-720.

[24] Sanders, N. J., Gotelli, N. J., Wittman, S. E., Ratchford, J. S., Ellison, A. M., Jules, E. S. (2007): Assembly rules for ant communities across spatial scales and habitats. - J. Biogeogr 34: 1632-1641.

[25] Schwerk, A. (2014): Changes in carabid fauna (Coleoptera, Carabidae) along successional gradients in post-industrial areas in Central Poland. - European Journal of Entomology 111: 677-685.

[26] Skalski, T., Pośpiech, N. (2006): Beetles community structures under different reclamation practices. - European Journal of Soil Biology 42: 317-320.

[27] Skalski, T., Stone, D., Kramarz, P., Laskowski, R. (2010): Ground beetle community responses to heavy metal contamination. - Baltic Journal of Coleopterology 10: 1-12. 
[28] Skalski, T., Kędzior, R., Maciejowski, W., Kacprzak, A. (2011): Soil and habitat preferences of ground beetles Coleoptera, Carabidae) in natural mountain landscape. Baltic Journal of Coleopterology 11: 105-115.

[29] Skalski, T., Kędzior, R., Kolbe, D., Knutelski S. (2015): Ground beetles as indicators of heavy metal pollution in forests. - Sylwan 159: 905-911.

[30] Skalski, T., Kędzior, R., Szwalec, A., Mundała, P. (2016): Do traditional land rehabilitation processes improve habitat quality and function? Life-history traits of ground beetles (Coleoptera, Carabidae) say no. - Periodicum Biologorum 118: 185-194.

[31] Skłodowski, J. (2009): Interpreting the condition of the forest environment with use of the SCP/MIB model of carabid communities (Coleoptera: Carabidae). - Baltic Journal of Coleopterology 9: 89-100.

[32] Skłodowski, J. (2017a): Manual soil preparation and piles of branches can support ground beetles (Coleoptera, carabidae) better than four different technical soil treatments in a clear-cut area of a closed-canopy pine forest in northern Poland. - Scandinavian Journal of Forest Research 32: 123-133.

[33] Skłodowski, J. (2017b): Three phases of changes in carabid assemblages during secondary succession in a pine forest disturbed by windthrow - results from the first 10 years of observations. - Insect Conservation and Diversity 10: 449-512.

[34] StatSoft (2012): STATISTICA (data analysis software system), version 12.0. www.statsoft.com.

[35] Stone, L., Roberts, A. (1990): The checkerboard score and species distributions. Oecologia 85: 74-79.

[36] Szyszko, J. (1983): Methods of macrofauna investigations. - In: Szujecki, A., Szyszko, J., Mazur, S., Perliński, S. (eds.) The process of forest soil macrofauna formation after afforestation of farmland. Warsaw Agricultural University Press, Warsaw, pp 10-16.

[37] Thiele, H. U. (1977): Carabid assemblages in their environments: A study on habitat selection by adaptations in physilogy and behavior. Stuttgard, Springer, pp 369.

[38] Tropek, R., Kadlec, T., Karesova, P., Spitzer, L., Kocarek, P., Malenovsky, I., Banar, P., Tuf, I. H., Hejda, M., Konvicka, M. (2010): Spontaneous succession in limestone quarries as an effective restoration tool for endangered arthropods and plants. - Journal of Applied Ecology 47: 139-147.

[39] Tropek, R., Kadlec, T., Hejda, M., Kočárek, P., Skuhrovec, J., Malenovský, I., Vodka, Š., Spitzer, L., Baňař, P., Konvička, M. (2012): Technical reclamations are wasting the conservation potential of post-mining sites. A case study of black coal spoil dumps. Ecological Engineering 43: 13-18.

[40] Ulrich, W., Komosińsi, K., Zalewski, M. (2008): Body size and biomass distributions of carrion visiting beetles: do cities host smaller species? - Ecology Research 23: 241-248.

[41] Vandewalle, M., de Bello, F., Berg, M. P., Bolger, T., Dolédec, S., Dubs, F., Feld, C. K., Harrington, R., Harrison, P. A., Lavorel, S., de Silva, P. M., Moretti, M., Niemelä, J., Santos, P., Sattler, T., Sousa, J. P., Sykes, M. T., Vanbergen, A. J., Woodcock, B. A. (2010): Functional traits as indicators of biodiversity response to land use change across ecosystems and organisms. - Biodiversity and Conservation 19: 2921-2947. 